\title{
Perbandingan Peramalan Dengan Metode Eksponensial Smoothing dan Winter Multiplicative Seasonality pada Data Penjualan Songkok Nasional UMKM di Kabupaten Gresik
}

\author{
The Forecasting Comparison between Exponential Smoothing and Winter Multiplicative \\ Seasonality Methods on SMEs Songkok Product Sales Data in Gresik Regency
}

\author{
Anik Rufaidah $^{1 *}$, Muhamad Afif Effindi ${ }^{2}$ \\ ${ }^{1}$ Universitas Qomaruddin, Jalan Raya Bungah No. 01 Bungah Gresik \\ ${ }^{2}$ Universitas Trunojoyo Madura, Jalan Raya Telang PO Box 2 Kamal Bangkalan \\ *anikrufaidah99@gmail.com, mafif.effindi@trunojoyo.ac.id
}

\begin{abstract}
Abstrak. Data penjualan songkok Nasional yang diproduksi oleh UMKM kabupaten Gresik selalu mengalami fluktuatif dan data tersebut juga berpengaruh adanya trend naik. Untuk mendeteksi penjualan kedepan yang berpengaruh dengan persediaan bahan baku. Sehingga kami menggunakan pemodelan dengan Double Exponential Smoothing dan Winter Multiplicative Seasonality. Dari hasil pemodelan ternyata nilai MAD dan MSD yang didapat terkecil adalah model Winter Multiplicative Seasonality, sehingga model tersebut kami buat forecasting untuk 6 bulan kedepan.
\end{abstract}

Kata Kunci: Double Exponential Smoothing, Winter Multiplicative Seasonality, forecasting.

\begin{abstract}
Data on National Songkok sales produced by Small and Medium Enterprises (SMEs) in Gresik Regency of East Java Province was always fluctuate and the data also influences the uptrend. In order to detect future sales which was affecting the inventory of raw materials, this research use modeling with Double Exponential Smoothing and Winter Multiplicative Seasonality. From the modeling results, it turns out the smallest value of MAD and MSD is the Winter Multiplicative Seasonality model. The data used by the model forecast for the next 6 months.
\end{abstract}

Keywords: Double Exponential Smoothing, Winter Multiplicative Seasonality, forecasting.

\section{Pendahuluan}

Songkok merupakan salah satu kebutuhan untuk muslim, serta sudah menjadi bagian dari salah satu dari sekian banyak pakaian nasional Indonesia. Kabupaten Gresik Provinsi Jawa Timur merupakan daerah pengrajin songkok nasional yang produknya sudah dijual dan dikenal secara luas baik di daerah sekitar, atau diluar daerah bahkan sudah sampai ke mancanegara. Banyaknya pengrajin UMKM di Kabupaten Gresik yang menghasilkan songkok tersebut sehingga ketertarikan untuk mengamati penjualan songkok tersebut.

Hasil pengamatan pada data penjualan songkok menunjukkan siklus yang fluktuatif. Penjualan hanya mengalami peak atau puncak pada bulan tertentu. Sehingga membentuk suatu model-model peramalan tertentu. Diperlukan suatu mekanisme peramalan untuk model penjualan yang dapat digunakan untuk menentukan belanja bahan dalam rangka pemenuhan kebutuhan dan persediaan bahan baku yang diperlukan oleh UMKM songkok tersebut.

Persediaan bahan baku merupakan bagian yang penting dalam suatu produksi [1], termasuk salah satunya produksi songkok nasional. Produksi songkok yang berlebihan juga dapat menyebabkan penumpukan jumlah barang sehingga biaya simpan juga bertambah akhirnya mengalami kerugian. Sehingga untuk mengatasi hal tersebut dapat dilakukan peramalan untuk bulan-bulan kedepan, yang 
akan digunakan untuk melihat persediaan bahan baku yang diperlukan.

Beberapa penelitian telah dilakukan oleh peneliti lain dalam rangka menentukan model pengendalian jumlah persediaan bahan baku [1], memberikan masukan bagi optimasi biaya total persediaan [2], memberikan masukan bagi optimalisasi produksi [3], peramalan produksi tanaman pangan [4], untuk menentukan penjualan produk terbaik [5], serta peramalan untuk kebutuhan pariwisata [6]. Pendekatan berbeda dilakukan di dalam penelitian ini. Antara lain dengan penerapan metode peramalan dengan double exponential smoothing yang digunakan melalui penggunaan pembobotan dan adanya trend dari data. Sedangkan model winter multiplicative digunakan dengan menggunakan pembobotan dan efek musiman yang selalu naik. Penelitian ini merupakan pekerjaan lebih lanjut dari pekerjaan pada paper sebelumnya [7] yang menggunakan analisis time series [8] [9] untuk menentukan model terbaik dari produk songkok nasional.

\section{Landasan Teori}

\subsection{Metode Double Exponential Smoothing}

Metode peramalan dengan menggunakan Double Exponential Smoothing digunakan untuk memberikan pembobotan pada data masa lalu secara berganda. Dimana pada metode ini pembobotan yang digunakan pada dasarnya sama dengan Single Exponential Smoothing, namun terdapat penambahan pembobotan yang digunakan untuk mendeteksi adanya trend dari data tersebut. Dengan model data sebagai berikut:

$$
\begin{gathered}
L_{t}=\alpha Y_{t}+(1-\alpha)\left(L_{t-1}+b_{t-1}\right) \\
b_{t}=\gamma\left(L_{t}-L_{t-1}\right)+(1-\gamma) b_{t-1} \\
F_{t+m}=L_{t}+b_{t} m
\end{gathered}
$$

Dimana pembobotan $\alpha$ dan $\gamma$ bernilai antara 0 da $1 . \boldsymbol{L}_{\boldsymbol{t}}$ menyatakan estimasi besarnya (level) menyatakan nilai ramalan pada waktu $t$, dan $\boldsymbol{b}_{\boldsymbol{t}}$ menyatakan nilai slope pada waktu $t$. Nilai pembobotan $\alpha$ dan $\gamma$ dapat ditentukan oleh user, namun dalam software telah dilakukan optimisasinya.

\subsection{Metode Winter}

Metode Winter dalam pembobotannya menggunakan tiga pembobotan yaitu $\alpha, \beta$ dan $\gamma$ yang bernilai antara 0 dan 1 . Dimana pembobotan nilai $\alpha$ digunakan pembobotan pada nilai peramalan, $\beta$ digunakan untuk pembobotan pada slope, $\gamma$ memberikan pembobotan pada efek musiman. Dimana model winter ini dapat dilakukan dua model yaitu Additive Seasonality. Sedangkan bila berdasarkan efek musiman berubah dari waktu ke waktu, maka model yang dapat dipakai adalah model Multiplicative Seasonality. Bentuk model yang digunakan adalah sebagai berikut:

\section{Additive Seasonality}

$$
\begin{array}{ll}
\text { Level } & : L_{t}=\alpha\left(Y_{t}-S_{t-s}\right)+(1-\alpha)\left(L_{t-1}-b_{t-1}\right) \\
\text { Trend } & : b_{t}=\beta\left(L_{t}-L_{t-1}\right)+(1-\beta) b_{t-1} \\
\text { Musiman } & : S_{t}=\gamma\left(Y_{t}-L_{t}\right)+(1-\gamma) S_{t-s} \\
\text { Ramalan } & : F_{t+m}=L_{t}+b_{t} m+S_{t-s+m}
\end{array}
$$


Multiplicative Seasonality

$$
\begin{array}{ll}
\text { Level } & : L_{t}=\alpha \frac{Y_{t}}{S_{t-s}}+(1-\alpha)\left(L_{t-1}-b_{t-1}\right) \\
\text { Trend } & : b_{t}=\beta\left(L_{t}-L_{t-1}\right)+(1-\beta) b_{t-1} \\
\text { Musiman } & : S_{t}=\gamma \frac{Y_{t}}{L_{t}}+(1-\gamma) S_{t-s} \\
\text { Ramalan } & : F_{t+m}=\left(L_{t}+b_{t} m\right) S_{t-s+m}
\end{array}
$$

\subsection{Kriteria Dalam Pemilihan Beberapa Metode Peramalan}

Dalam melakukan peramalan diterapkan beberapa metode secara bersama-sama, untuk mencari metode yang terbaik dalam pemilihan kriteria yang dipakai acuan untuk menentukan model terbaik. Dalam melakukan peramalan, baik tidaknya model yang digunakan sangat berpengaruh dalam pengambilan keputusan yang dilakukan. Dengan melihat tingkat kesalahan terkecil dari model yang dapat dipilih dalam melakukan prediksi di masa yang akan datang. Besarnya kesalahan tersebut dapat dihitung dengan ukuran tingkat kesalahan:

1. MAPE (Mean Absolute Percentage Error), yaitu presentasi kesalahan dengan melihat seberapa besar nilai peramalan dibandingkan dengan nilai sebenarnya. Yang mana nilai ini digunakan pada data0data yang mempunyai skala interval berbeda.

$$
M A P E=\frac{\sum_{i=1}^{n}\left|\left(y_{t}-\hat{y}_{t}\right) / y_{t}\right|}{n} \times 100
$$

2. MAD (Mean Absolute Deviation), yaitu mengukur kesalahan dengan merata-ratakan absolut kesalahan peramalan. Kesalahan yang diukur dalam pengukuran ini akan sama dengan data aslinya dan digunakan untuk membandingkan antar metode peramalan yang berbeda.

$$
M A D=\frac{\sum_{t=1}^{n}\left|y_{t}-\hat{y}_{t}\right|}{n}
$$

3. MSD (Mean Squared Deviation), yaitu nilai pengukuran kesalahan peramalan yang mana penyebut $n$ tanpa memperhatikan derajat bebas dari model. Yang mana perhitungan kesalahan ini digunakan untuk membandingkan peramalan antar metode.

$$
M S D=\frac{\sum_{t-1}^{n}\left(y_{t}-\hat{y}_{t}\right)^{2}}{n}
$$

\section{Metodologi Penelitian}

\subsection{Langkah-langkah Penelitian}

Dalam pemodelan data penjualan songkok nasional di UMKM Gresik dengan menggunakan data penjualan pada bulan Januari 2017 sampai dengan Juni 2018. Dalam melakukan pemodelan peramalan untuk mendapatkan prediksi yang akan datang dilakukan langkah-langkah sebagai berikut:

1. Melakukan plot time series untuk mengetahui pola data penjualan songkok

2. Melakukan peramalan dengan model Double Exponential Smoothing pada data penjualan songkok mulai Januari 2017 sampai Juni 2018

3. Melakukan peramalan dengan metode Winter Multiplicative Seasonality pada data penjualan songkok mulai Januari 2017 sampai Juni 2018 
4. Melakukan perhitungan nilai MAD dan MSD pada masing model peramalan

5. Memilih model terbaik yang digunakan dengan melihat nilai MAD dan MSD terkecil

6. Meramalkan untuk 6 bulan kedepan.

\subsection{Analisis Penelitian}

Data yang digunakan dalam penelitian ini adalah data penjualan Songkok Nasional pada UMKM di Kabupaten Gresik pada data penjualan Januari 2017 sampai Juni 2018. Dimana penjualan yang tidak menentu sehingga seringnya order yang begitu banyak dengan persediaan barang yang kurang memenuhi pesanan, adakalanya banyaknya pembuatan songkok yang dihasilkan dan berkurangnya pemesanan sehingga mengakibatkan penumpukan barang yang ada. Sehingga hal tersebut dapat penulis lakukan peramalan ke depan untuk pemenuhan kebutuhan pasar, dimana yang pertama dilakukan adalah dengan melihat pola data yang ada.

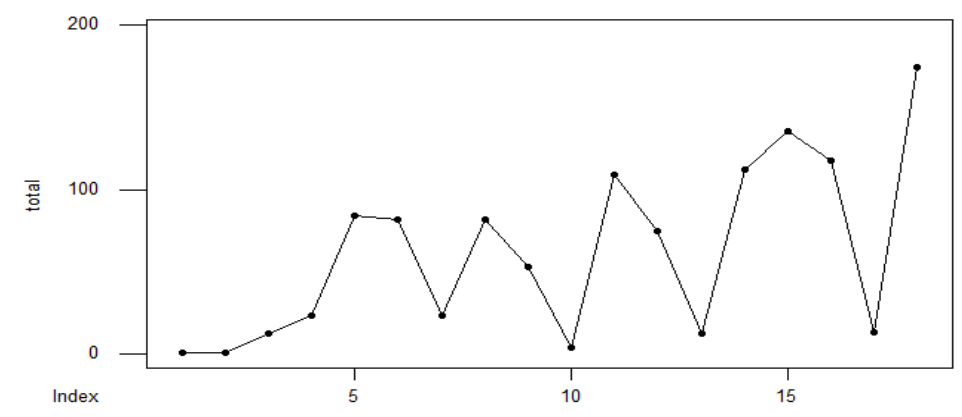

Gambar 1. Plot Time series

Dapat dilihat dari plot time series dapat penjualan songkok pada Gambar 1, yang mana data tersebut mengalami pola fluktuatif yang musiman 4 bulanan dan data tersebut juga mengikuti pola trend naik. Untuk mengetahui peramalan ke depan dilakukan peramalan dengan metode Double Exponential Smoothing dan Winter Multiplicative Seasonality kedua model tersebut dibandingkan mana model yang paling sesuai dari kedua model tersebut.

\section{Pembahasan}

\subsection{Pemodelan Dengan Double Exponential Smoothing}

Pada data penjualan Songkok Nasional hasil UMKM di kabupaten Gresik pada data mulai bulan Januari 2017 sampai Juni 2018 dilakukan metode peramalan Double Exponential Smoothing karena pola data tersebut dapat dilihat adanya pola musiman dan adanya trend naik. Dengan menggunakan Software MINITAB dengan menggunakan metode optimum untuk menentukan nilai estimasi slope $\alpha$ dan $\gamma$ didapat hasil perhitungannya.

Tabel 1. Model Double Exponential Smoothing

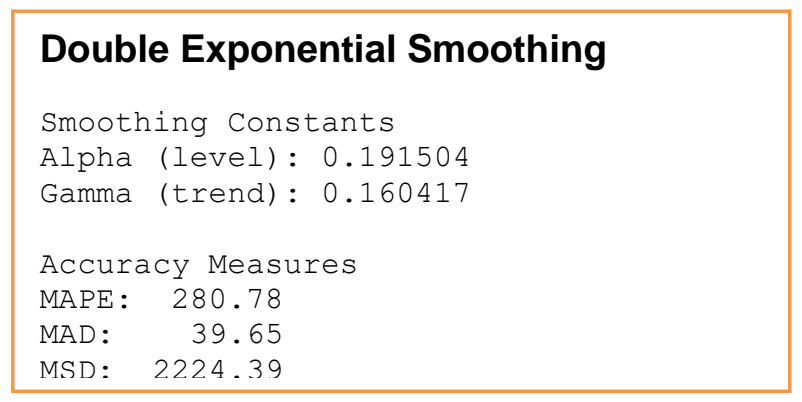


Dari hasil perhitungan diatas didapat model dari model peramalan Double Exponential Smoothing dengan hasil model sebagai berikut:

$$
\begin{gathered}
L_{t}=0,1915 Y_{t}+(1-0,1915)\left(L_{t-1}+b_{t-1}\right) \\
b_{t}=0,1604\left(L_{t}-L_{t-1}\right)+(1-0,1604) b_{t-1} \\
F_{t+m}=L_{t}+b_{t} m
\end{gathered}
$$

Dengan hasil plot taksiran model sebagai berikut, dimana pada garis tengah menunjukkan nilai taksiran model, sedangkan pada garis hitam menunjukkan plot data asli.

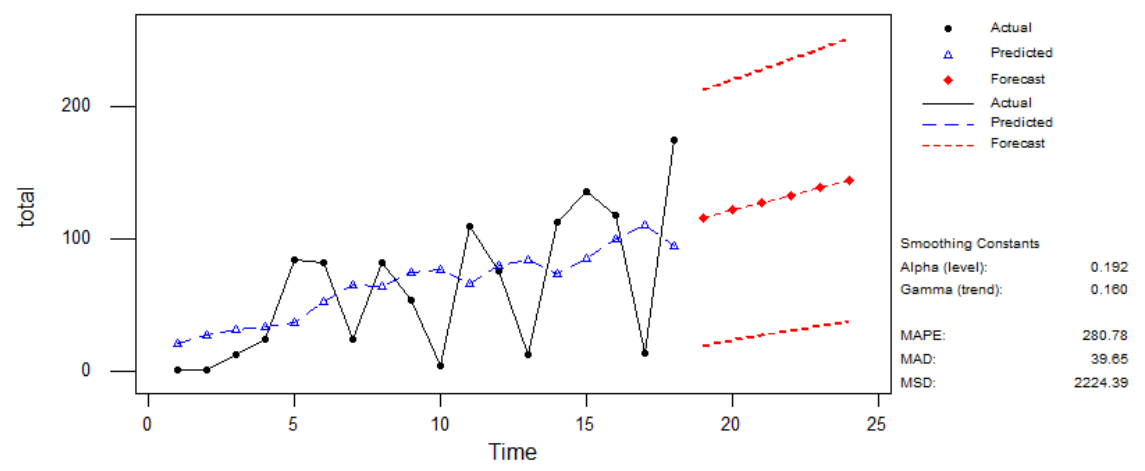

Gambar 2. Plot model Double Exponential Smoothing

\subsection{Pemodelan Dengan Winter Multiplicative Seasonality}

Untuk pemodelan data penjualan Songkok Nasional pada UMKM di Kabupaten Gresik Pada data penjualan mulai bulan Januari 2017 sampai Juni 2018 dilakukan pemodelan dengan menggunakan Winter Multiplicative Seasonality. Dengan menggunakan perhitungan MINITAB didapat hasil perhitungan sebagaimana Tabel 2.

Tabel 2. Model Winter Multiplicative Seasonality

\begin{tabular}{l} 
Winters' multiplicative model \\
Smoothing Constants \\
Alpha (level): 0.05 \\
Gamma (trend): 0.05 \\
Delta (seasonal) 0.05 \\
Accuracy Measures \\
MAPE: 178.97 \\
MAD: 28.64 \\
MSD: 1867.97 \\
\hline
\end{tabular}

Dari model tersebut didapat hasil pemodelan Winter Multiplicative Seasonality dengan nilai slope 0,05 sebagai berikut:

Level

$$
: L_{t}=0,05 \frac{Y_{t}}{S_{t-s}}+(1-0,05)\left(L_{t-1}-b_{t-1}\right)
$$

Trend

$$
: b_{t}=0,05\left(L_{t}-L_{t-1}\right)+(1-0,05) b_{t-1}
$$

Musiman

$$
: S_{t}=0,05 \frac{Y_{t}}{L_{t}}+(1-0,05) S_{t-s}
$$

Ramalan

$$
: F_{t+m}=\left(L_{t}+b_{t} m\right) S_{t-s+m}
$$


Dari hasil plot untuk pemodelan Winter Multiplicative Seasonality didapat grafik garis biru yang berasal dari taksiran model yang didapat, sedangkan garis hitam merupakan data aktualnya.

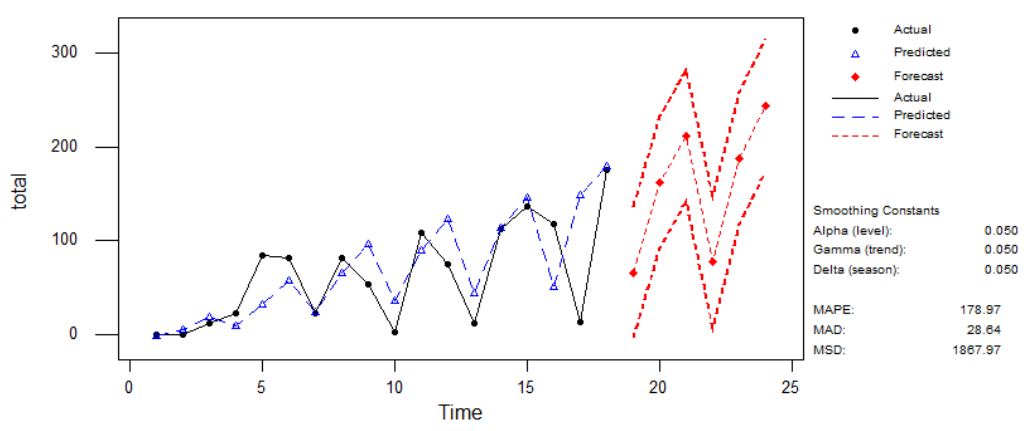

Gambar 3. Plot model Winter Multiplicative Seasonality

Perbandingan nilai MAD dan MSD pada perhitungan model Double Exponential Smoothing dan Winter Multiplicative Seasonality dengan menggunakan perhitungan MINITAB, yang terdapat pada tabel 3. Dari data tersebut dapat dilihat bahwa untuk model Double Exponential Smoothing yang menghasilkan nilai MAD 39,65 dan MSD 2224.39, sedangkan model peramalan Winter Multiplicative Seasonality nilai MAD 8,64 dan nilai1867.97. Dari nilai tersebut dapat dilihat bahwa nilai MAD dan MSD yang kecil adalah model Winter Multiplicative Seasonality, maka model yang digunakan untuk peramalan kedepan adalah model Winter Multiplicative Seasonality.

Tabel 3. Nilai MAD dan MSD

\begin{tabular}{ccc}
\hline Model & MAD & $M S D$ \\
\hline Double Exponential Smoothing & 39,65 & 2224,39 \\
& & 1867,97 \\
\hline Winter Multiplicative Seasonality & 28,64 & \\
\hline
\end{tabular}

\subsection{Forecasting Model Winter Multiplicative Seasonality}

Dari hasil pemodelan dengan Winter Multiplicative Seasonality dapat digunakan untuk peramalan 6 bulan kedepan dengan hasil peramalan terdapat dalam Tabel 6. Sedangkan untuk plot hasil peramalan modelnya terdapat dalam Gambar 3.

Tabel 4. Peramalan 6 bulan kedepan.

\begin{tabular}{|rrrrr|}
\hline Row & Period & Forecast & Lower & Upper \\
1 & 19 & 65.774 & -4.391 & 135.940 \\
2 & 20 & 161.753 & 91.499 & 232.007 \\
3 & 21 & 211.964 & 141.619 & 282.309 \\
4 & 22 & 76.994 & 6.556 & 147.432 \\
5 & 23 & 187.860 & 117.328 & 258.393 \\
6 & 24 & 244.429 & 173.798 & 315.059 \\
\hline
\end{tabular}




\section{Kesimpulan}

Untuk memodelkan peramalan kedepan dari data penjualan songkok nasional yang diproduksi oleh UMKM Songkok Nasional di Kabupaten Gresik. Hal tersebut dengan melihat adanya pola data yang musiman dan mengikuti trend naik, sehingga kami menggunakan model Double Exponential Smoothing dengan nilai parameter $\alpha=0,1915$ sebagai nilai levelnya dan $\gamma=0,1604$ sebagai nilai trennya dan Winter Multiplicative Seasonality didapat nilai parameter $\alpha=0,05$ untuk nilai level, $\gamma=$ 0,05 untuk level trend dan $\delta=0,05$ untuk level musiman. Dari kedua model yang digunakan ternyata nilai MAD dan MSD terkecil adalah model Winter Multiplicative Seasonality, maka forecasting 6 bulan kedepan menggunakan model tersebut.

\section{Referensi}

[1] FH Badruzzaman dan E Harahap, "Pengendalian Jumlah Persediaan Bahan Baku Kerudung pada RAR Azkia Padalarang," Jurnal Matematika, vol. 17, no. 1, pp. 35-39, 2018.

[2] MG Fatkhurrokhman, MY Fajar, dan Y Ramdani, "Optimasi Biaya Total Persediaan dengan Permintaan Bersifat Linier," Jurnal Matematika, vol. 1, no. 1, 2016.

[3] R Haslan, N Supriadi, dan SP Nasution, "Optimalisasi Produksi Kopi Bubuk Asli Lampung dengan Metode Simpleks," Jurnal Matematika, vol. 17, no. 2, 2018.

[4] P Ariyanto dan Erikawati, "Penerapan Metode Double Exponential Smoothing pada Peramalan Produksi Tanaman Pangan," Jurnal Informatika Polinema, vol. 4, no. 1, 2017.

[5] E Fani, FA Widjajati, dan Soehardjoepri, "Perbandingan Metode Winter Eksponensial Smoothing dan Metode Event Based untuk Menentukan Penjualan Produk Terbaik di Perusahaan X," JURNAL SAINS DAN SENI ITS, vol. 6, no. 1, pp. A1-A5, 2017.

[6] U Dhoriva dan Suhartono, "Model Varma (Vector Autoregressive Moving Average) untuk Pemodelan dan Peramalan Data Deret Waktu di Bidang Pariwisata." Laporan Penelitian Dosen Muda UNY, 2007.

[7] A Rufaidah dan MA Effindi, "Analisis Time Series untuk Menentukan Model Terbaik Produk Songkok Nasional di Kabupaten Gresik," in Prosiding Seminar Nasional Matematika dan Terapannya 2018, Purwokerto, 2018, vol. 1, pp. 1-16.

[8] RD Peng, "A Method for Visualizing Multivariate Time Series Data," Journal of Statistical Software, vol. 25, no. 1, pp. 1-17, 2008.

[9] G Box, G Jenkins, and G Reinsel, Time Series Analysis. Prentice Hall, 1994. 